Artículos

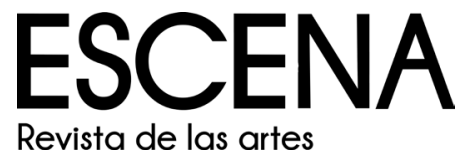

Publicación semestral. ISSN 1409-2522

Volumen 76 - Número 2

Enero - Junio 2017

\title{
El flaneo virtual a través de Google Street View como una práctica artística
}

\author{
Rodolfo Rojas Rocha
}

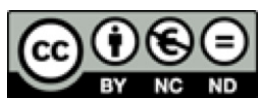

Esta obra está bajo una licencia Creative Commons

Reconocimiento-No comercial-Sin Obra Derivada 
Artículos

\title{
El flaneo virtual a través de Google Street View como una práctica artística
}

\author{
Rodolfo Rojas Rocha \\ Universidad Laval, Canadá \\ rodolfo.rojasrocha@ucr.ac.cr
}

Recibido: 28 de setiembre de 2016 Aprobado: 28 de octubre 2016

\begin{abstract}
Resumen
Este artículo propone una descripción de la ruta virtual como una práctica artística. Esta se explica por el flaneo digital, que se recrea a través de la pantalla del ordenador en tanto que imagen de la web, funcionando como espacio de manipulación de referentes geográficos y orientando el desarrollo puntual de una obra. Dentro de este análisis se identifican tres categorías de flâneur: premoderno, moderno y contemporáneo. Luego se delimitan los dos tipos de walkscapes virtuales seguidos de la manipulación de los referentes geográficos, con el fin de establecer estrategias de producción visual. El primer aspecto, considera el paseo virtual como experiencia de recolección de datos realizada por los agentes que capturan las imágenes urbanas, estudiando las operaciones itinerantes en el Google Street View. La segunda operación, (realizada por el usuario o flâneur final) es determinada por la recolección de esa información pertinente que ayuda a la elaboración proyectual de la obra plástica o visual en potencia, en el contexto del laboratorio. Se trata de ir coleccionando una serie de patrones, de territorios, paisajes modernos y calles aglomeradas, fotografiados en 360 grados, por medio de los cuales se dispone un conjunto de rutas urbanas concretas. Interesa, también, la manipulación de imágenes digitales en las que el andar sobre las fotos instaura un estado de simulacro gracias a la acción operativa sobre la imagen capturada. En fin, este paseo por Street View permite reconocer unos sistemas ópticos como abstracciones plásticas, que nacen de pantallas interactivas mediante el empleo de recursos de la web social.
\end{abstract}

Palabras clave: flâneur; Google Street View; el andar virtual; creación 


\begin{abstract}
This article analyzes the virtual path as an artistic practice. We explain it through the concept digital flânerie. The latter is recreated on the computer screen as an image of the web, which functions as a geographical reference that guides the development of a work. Within this analysis, three categories of flâneur are identified: a) pre-modern, b) modern, and c) contemporary. Also, we present two types of virtual walkscapes, following the manipulation of geographic images in order to establish visual strategies. The first aspect to consider is the virtual tour as an experience of data collection by the agents that capture urban images and study Google Street View. The second operation-performed by the user, or flâneur final- is determined by the collection of the relevant information that aids in the development of a visual work in the context of the laboratory. This is going collecting a series of patterns territories, modern landscapes and busy streets, photographed in 360 degrees, through which a set of specific urban routes are made available. We are also interested in the manipulation of digital images where walking on the photos establishes a state of drill, due to the operational action on the captured image. This walk through Street View allows us to recognize some optical systems, such as abstractions and interactive displays, by using resources from the social web.
\end{abstract}

Keywords: flâneur; Google Street View; the virtual walk; creation 
Artículos

\section{Categorías de flâneur: premoderno, moderno y contemporáneo}

El walkscape constituye un tipo de flânerie. Ambos se centran en el andar que integra un conjunto de acciones que se desarrollan durante la investigación-creación. Este artículo reflexiona sobre el desplazamiento virtual como una práctica estética. En este sentido, se parte de un punto fijo localizado en el Google Street View y se realiza, desde este motor de búsqueda geo-localizada, un viaje virtual por medio de imágenes digitales. En este viaje nos proponemos generar prácticas creativas buscando patrones visuales comenzando con el concepto de módulo. Los módulos son encontrados en las fotos que se tocan y se seleccionan a partir de derivas gráficas hasta atinar las posibles soluciones visuales mediante composiciones pictóricas, instalaciones video gráficas, y fotográficas. Podría decirse que esta marcha virtual implica una exploración de ambientes y de territorialidades en constante movimiento. Se propone utilizar los diversos tipos de andar sobre el territorio mediante el ordenador y la pantalla-global (Soulages, 2011, p. 49), principalmente, en la navegación por la web, dentro de la que se incluyen distintas maneras de desplazamiento controlado en el espacio urbano, el cual es representado por mapas digitales.

Asimismo, en este artículo, se intenta hacer una descripción reflexiva de las estrategias de flânerie utilizadas, así como los pasos de búsqueda y de reconocimiento de fotos virtuales tomada de Google Street View, que, como motor de geo-localización, se transforma en una base de datos de topografías urbanas y naturales. Para este fin, se proponen dos ejes temáticos que abarcan la relación entre experiencia sobre la foto urbana y su manipulación. El primer eje busca describir el "flaneo virtual" tomando en cuenta los aspectos asociados al andar. El segundo eje abarca la imagen de la web y la manipulación de los referentes geográficos que conllevan a la producción estética.

En primer lugar, el andar se redefine como una práctica de movilización y espacio del "eterno errar" (Careri, 2002, p. 42) realizada por nuestro cuerpo o por medios mecánicos, tecnológicos o digitales en referencia a la cultura móvil (seres, objetos, símbolos, informaciones). Esta acción fundamental es comprendida "como una herramienta crítica, como una manera obvia de mirar el paisaje, como una forma de emergencia de cierto tipo de arte y de arquitectura" (p. 11).

Se pueden establecer tres tipos de andar que responden a valores culturales e históricos asociados a los territorios y sus idiosincrasias. De hecho, la marcha (corporal, mecánica y digital) se define en función de ciertas prácticas de movilización que conllevan al establecimiento de modelos de translación material e inmaterial con fines simbólicos. 
Se diría que la marcha premoderna, operada por necesidades biológicas o morfológicas, se caracteriza también por ser un andar básico, simple, asociado a los hábitos determinados por la naturaleza. Esta marcha constituye, sobre todo, una acción orgánica, puesto que se integra al paisaje propiamente dicho, correspondiendo a un tipo de vivencia caracterizada por las sociedades movedizas, nómadas (paleolíticas y neolíticas), y sedentarias de labranza que se vinculan a diversas prácticas de organización del tiempo: cultivar la tierra basadas en las tradiciones mágico-religiosas. De este modo, el caminar peregrino, migratorio, guerrero y comercial dispone de unas fórmulas de transitar, las cuales modifican sustancialmente los usos del paisaje natural y del cuerpo acostumbrado al caballo y animales de carga. Desde el punto de vista operativo y morfológico, este andar arcaico puede incluir en diferentes grados: de exploración, de conquista, de supervivencia, de asentamiento, entre otros, emparentados a un panorama abierto sin marcos ópticos. El walkscape constituye, por tanto, una dominación del entorno:

La acción de atravesar el espacio nace de la necesidad de moverse con el fin de encontrar alimentos e informaciones indispensables para la propia supervivencia. Sin embargo, una vez satisfechas las exigencias primarias, el hecho de andar se convirtió en una acción simbólica que permitió que el hombre habitara el mundo. Al modificar los significados del espacio atravesado, el recorrido se convirtió en la primera acción estética que penetró en los territorios del caos, construyendo un orden nuevo sobre cuyas bases se desarrolló la arquitectura de los objetos colocados en él. Andar es un arte que contiene en su seno el menhir, la escultura, la arquitectura paisaje (Careri, 2002, p. 11).

La marcha moderna va seguida de la mecanización de los aparatos de desplazamiento (ferrocarril, estación, automóvil, avión) que reorganizan las rutas geográficas de los caminos. Es un andar del dispositivo, del tiempo medido por instrumentos de precisión, de la zona de confort, que responde, más bien, a los procesos de banalización del cuerpo dentro del imaginario urbano. Esta postura intenta ser modelada a partir de un miramiento literario, comenzando con el contexto de la ciudad que se convierte en espectáculo sensorial para ser escrito. De ahí viene el término de flâneur, que tiene implicaciones más allá del simple desplazamiento motriz, es como un síntoma cultural, más bien un indicio de la sistematización del espacio organizado por la técnica. El ideal de la modernidad, sobre todo el de la lectura poética que realiza Charles Baudelaire (2010) en el Pintor de la vida moderna, propone un encuentro necesario entre el caminante apasionado y su desplazamiento azaroso sin objetivo preciso en busca de lo desconocido, apoyándose en la mirada narrativa, en la pulsión óptica de la ciudad de vidrio y de metal. Esta idea de panorama sensorial narrado se asocia a un caminante urbano, a un noble dandy (Cuvardic, 2009, p. 22), al poeta e intelectual, al obrero marginal, al artista callejero y al 
errabundo creativo que mira las perspectivas de los bulevares de París, concebidos por Haussmann en el siglo XIX ${ }^{1}$.

Ya no cabe un pensamiento de pueblo pequeño dentro de las nuevas calles amplias flanqueadas de árboles y jardines alrededor de monumentos simbólicos que sintonizan con la Belle Époque. Un mundo visual totalizante, plural y complejo que toma en cuenta la perspectiva urbana de origen renacentista mezclada con la estética barroca. En este contexto, se observa la saturación racionalizada de los parterres viales inspirados de patrones geométricos neoclásicos pero con ciertos aires de las primeras cinematografías. Las multitudes de esta época de ocio circulan por las rutas de estilos heteróclitos aún a sabiendas de que muchas galerías cautivan la mirada de los nuevos deambuladores "vagabundos" (Maffesoli, 1985, p. 27) quienes comienzan a poseer un estilo de vida basado en la comodidad, la frivolidad y el ocio. Esto trae la resistencia y el surgimiento de una ansiedad individual frente a la ciudad-espectáculo que se convierte en espacio familiar (Cuvardic, 2009, p. 23), en centro del lujo burgués industrial, en pompa de hierro y de vidrio que democratiza excluyendo a la vez.

El andar moderno expone la evolución de los artefactos de proyección de luz que permiten asociar, en cierto sentido, las representaciones filmadas o capturadas por las cámaras de exposición e impresiones lumínicas de los nuevos medios pre-cinematográficos. Un andar que es modificado por el movimiento mecánico de imágenes luminosas, en las que el emergente régimen escópico de máquinas de visión (Poissant, 2008) reconstituye los modos perceptuales y kinéticos (auditivo y táctil) de desplazamiento del cuerpo, sustentando la lógica de las pantallas y el registro fotográfico de los ambientes urbanos.

Simay propone, desde la visión "benjaminiana" (2009, p. 77), una crítica a ciudad y a la idea del espacio urbano como experiencia. Con la reforma de París y la implementación de propuestas urbanas afrancesadas en Latinoamérica (Buenos Aires, México D. F. y São Paulo), comienza a transformarse el habitar en espectáculo óptico (Cambier, 2009, p. 12), en vitrina de exhibición, en rutinas sensoriales que hacen accesible la marcha para ver y ser visto, donde la mirada se torna en mercancía. El caminar ya no es el mismo, sino que surge un andar (en línea recta hacia puntos de fuga) diferente que implica una necesidad de devorar el entorno óptico mientras se circula. No obstante, surge una lectura paralela, una visión anti-utópica y dramática de lo urbano que asume una estética ef ímera y anónima asentada en la cultura visual de las metrópolis en crisis. Esta noción de antropofagia ocular, desde el discurrir del itinerario, se presenta a partir del pesimismo del anti-progreso y la aparición de la contradicción social. Esta

\footnotetext{
${ }^{1}$ Consultar https://www.google.com/intl/fr/maps/streetview/
} 
contradicción es vinculada directamente a las microbiografías que acontecen al unísono en la ciudad de masas. Debe destacarse también que todo se resume en una revisión del pasatiempo, sus detalles fastuosos, sus vivencias mundanas, sus sitios ruinosos, catastróficos, fantasmagóricos y pobres (Simay, 2009, p. 76).

El artista, por tanto, experimenta una estimulación iconográfica que se revela conjuntamente con sus usos directos del pasaije urbano a partir de extractos, libretas de éxodos y bosquejos de perspectivas metropolitanas. El concepto baudelairiano de flânerie, emparentado a la movilización de gente, permite comprender también el carácter comunitario del artista caminante. En cuanto a los referentes literarios del caminante con sentido (Cuvardic, 2009), se toman en cuenta las tácticas del callejeo poético como práctica simbólica y retórica del paseo, en el cual se establece una relación entre los personajes implicados, sobre todo, un vínculo evidente con el escritor andante, quien busca comprender la ciudad a través de sus crónicas y prosas urbanas. Este callejeo genera una colección de conocimientos metafóricos sobre la colectividad. Además, un diario de vida que recopila las travesías que integran un sistema de valores como el romanticismo, la libertad de circulación, la alegría de vivir, la miseria humana y la belleza.

El artista plástico del siglo XIX, específicamente, constituye el arquetipo del transeúnte moderno. Él encarna el personaje furtivo que se mezcla con la gente, admira el arrebato visual de la fotografía buscando la observación directa y la interpretación compositiva-visual de la esfera pública. En este sentido, se pensaría en los pintores impresionistas y post-impresionistas que se inmutan ante las materialidades artificiales de los panoramas transformados por la máquina de vapor, los efectos del color fragmentado y la luz producidos por los climas diversos. Él visita centros de recreación, ferias, museos y cafés. Su obsesión, asociada al hedonismo de la marcha, se bifurca en un personaje de rambla, de ambiente suburbano y bohemio que hace de las suyas sobre las aceras perfiladas. De hecho, los medios de comunicación, la movilización de peatones y los dispositivos de transporte público (locomotora, tranvía, bicicleta) transforman a ese individuo moderno en emblema del andante sin rumbo fijo, que gusta de las prácticas del hedonismo visual a través de representaciones pictóricas y de impresiones ópticas que van en contra de la perspectiva lineal tradicional y la academia del dibujo.

Sin embargo, con el desarrollo tecnológico moderno de los medios de transporte, el flaneo comienza a decrecer. Hay una predominancia del automóvil en la ciudad, desplazando las prácticas de caminar a sectores más privados dentro del contexto del Banlieue. Allí, se repite la marcha integrada a los patrones de la urbe-máquina utilizando la línea recta (Brusatin, 2002, p. 183), cúbica, modular y geométrica condicionada por el esquema calculado de las vías de la autopista. Surge el paseo sistemático del peatón y del auto que comparten el mismo espacio 
de circulación, por lo tanto, esta noción del andar moderno deja de lado, paradójicamente, al cuerpo frágil de la persona. El progreso científico, la arquitectura y la reproducción técnica ponen en evidencia la desaparición de la corporeidad, la cual se integra al dispositivo mecánico, a los módulos urbanos de estructuración, a los valores democratizadores de los dispositivos y a la mecanización de la anatomía humana sujeta al movimiento del motor. En este sentido, la industrialización concibe diversos usos del cuerpo cuando camina, corre, traza, danza y flanea (piéton, joggeur, traceur, danseur, flâneur) (Nuvaloti, 2009, p. 4). Estos usos modifican las funciones de los objetos urbanos (mueblería, señales de tránsito, arquitectura), aumentando nuestras capacidades de traslación más allá de las posibilidades físicas.

Seguidamente, la marcha contemporánea se altera conjuntamente con el desarrollo del ordenador y la eclosión de internet. Esta tiene que ver con el andar conceptual de la sociedad de la información; un andar de procesos fragmentados determinados por el buscador en la web y el código binario. Nos movemos, en este caso, por medio de una base de datos, dejando de lado nuestro cuerpo y asumiendo la mirada como motor de desplazamiento determinado por nuestro "ojo tecnológico" (La Rocca, 2011). Acá el andar es reducido a llevar los dedos al teclado y el ojo trabaja intensamente ejerciendo una función significativa sobre los dispositivos móviles. En esta tercera fase, la marcha se torna cognitiva y sedentaria, la pantalla se presenta como herramienta, un procedimiento, un saber híbrido e invención (Vial, 2013, p. 31) "En la dirección de una red fluida en el que los individuos crean su propia relación con la sociedad" (La Rocca, 2011, p. 78) dentro de una "nueva ecología de la comunicación visual digital" (p. 111).

Hay un interés, sobre todo, por las navegaciones dentro del ordenador a partir de acciones precisas, que hacen pensar lo ef ímero de la cultura digital, la cual obliga a repensar los ritos cotidianos y los ritos oculares. Se invita a navegar en el mar de páginas web orientadas por la interface, utilizando los medios electrónicos expandidos que se organizan por motores de búsqueda geográficos, donde la mente se mueve a un ritmo distinto al corporal mediante el reflejo de nuestro ojo. Más conocido aún es el camino de pantalla que se torna en una cacería de retos y de pulsiones, saltando obstáculos, encontrándose con imprevistos que hay que doblegar en cada distancia recorrida. Esa pantalla ofrece unas rutas inusuales desde diversos ángulos, siendo lo más realista y lo más mimético posible. Es un simulador de escenarios, de ciudades y territorios del mundo, indagando una óptica exploradora en forma de mosaico. Este es el camino de la ruta visual: una visita que se desmaterializa debido a la cooperación de dispositivos de visión.

Allí, se entra a la ciudad inconsciente mediante pantallas, una urbe que existe solamente por estos dispositivos de información visual en la que se exploran sus recovecos recreados, impensables de penetrar corporalmente, unos laberintos de datos tridimensionales. Sí, es posible penetrar estos mapas virtuales sin que ello implique mover el cuerpo, por lo tanto, se podría 
asociar este ejercicio visual a la marcha abstracta y surrealista (Careri, 2002, p.88) recurriendo a derivas gráficas que se orientan a partir de lo desconocido, la sorpresa y el descubrimiento afortunado. Cuando las pantallas de la geografía se muestran, se activan unas dinámicas del ojo, entre ellas una visión mosaico, que pretenden experimentar lo urbano en fragmentos de tiempo. Este andar virtual discontinuo obedece a este propósito. Los diversos tipos de desplazamientos involuntarios, que se organizan en universos paralelos, compuestos de simulaciones táctiles y juegos laberínticos descentrados, quedan sujetos al trazo de este caminante óptico. Lo anterior implica la búsqueda de itinerarios infinitos por la pantalla desmaterializada del ordenador en la que el "promeneur numérique" (Doueihi, 2008, p. 257), realiza una crónica de la navegación lúdica, en la indagación sin rumbo fijo, sin interrupciones pre-establecidas y sin final previo.

Es, por supuesto, a través de esta enciclopedia geográfica ficticia que se penetra a un posible orden controlado, por una gramática del espacio urbano real fotografiado. Hay que recordar que este régimen de representaciones está compuesto de estrategias de seducción visual, que implican una "fascinación por las sensaciones instantáneas" de los paseos (Hahn, 2006, p. 68), permitiendo la "experiencia urbana" (Lauster, 2007, p. 139), que se registra mediante impresiones y "notas de viaje" (Berdet, 2012, p. 430). De ahí que, por ejemplo, el flâneur contemporáneo hace recorridos tocando las imágenes a partir de parámetros pictóricos (perspectiva) y sensoriales (cromo-motriz) redefinidos por la lógica de la composición fotográfica.

\section{Los walkscapes virtuales y la manipulación de los referentes geográficos}

\section{Los walkscapes virtuales o flânerie virtual}

Se diría que los walkscapes son caminatas en el entorno urbano o natural. Estas constituyen una experiencia estética particular y "una herramienta crítica, como una manera obvia de mirar el paisaje" (Careri, 2003, p. 10). Son itinerarios de caminos que se transforman en rutinas del andar, en el sentido que dan cuenta de acciones de movilización que orientan experiencias estéticas y expresivas.

Cuando estos recorridos se realizan por medio de mapas numéricos enmarcados dentro de las Tecnologías de la Información y Comunicación (TIC), en la soledad de la pantalla bidimensional del ordenador se pueden instaurar rutinas de captura óptica y de transferencia de información métrica. Las cuales se convierten en materia prima visual del mundo representado. Acá, se describen las operaciones nómadas dentro del globo terráqueo por medio del pegman, que ayuda a la búsqueda y a la manipulación de imágenes digitales y que anda sobre las 
fotos generando un desdoblamiento del cuerpo. El cuerpo se libera hacia espacios distribuidos, estableciendo un desplazamiento por medio de una simulación por fotos gracias a la acción cinemática del montaje efectuado por múltiples cámaras instantáneas y simultáneas del Google car y otros dispositivos móviles (mochila, moto, barco, drones, satélite, vagón, estación).

Los walkscapes virtuales permiten coleccionar una serie de patrones de los territorios globales organizados en secuencias y en tomas por las fotografías panorámicas de 360 grados, las cuales establecen una visión esférica, en todas las direcciones, de rutas urbanas. Además, el archivo fotográfico como dispositivo icónico reconstruye un ambiente verosímil que observa y examina, oscilando a la vez en "imagen de control" (Limare, 2015, p. 67). Esta imagen conquista el espacio capturado por la mirada interactiva y establece pautas de supervisión a partir de secuencias descontinuas provocadas por el ensamblaje de fotos fijas en el sistema operativo. En este sentido, entonces, transitar el contorno espacial de un territorio como una práctica de fotos vigilantes, podría ser el punto de partida hacia el entendimiento del aspecto cinético de los registros fotográficos. Las fotos y videos se montan en línea, capturando cada detalle de la cotidianidad callejera y de los fenómenos que acontecen alrededor, provocando unas secuencias que capturan sin autorización e inmediatamente la vida privada de los transeúntes. Entre más se registra el espacio público, más desconfianza (o lo contrario) se obtiene y se termina modificando el ambiente de internet, en consecuencia, la dinámica de los walkscapes virtuales. Esto confirma la predominancia evolutiva de la sociedad de dominio visual en la cual todo "se controla, se traza, se filma, se enumera y se fotografía" (Limare, 2015, p. 69).

Se pueden distinguir dos categorías de flânerie por Google Street View: el fotográfico que captura las imágenes en tiempo y espacio real y el cibernauta quien se transforma en flâneur virtual. En primer lugar, el fotógrafo de Google dispone de dispositivos rodantes, el automóvil y la video-mochila denominada Google Street View Trekker, un dispositivo móvil que dirige la recolección de imágenes espaciales in situ y en tiempo de marcha. También, se toma en cuenta el usuario del sitio web Panoramio quien comparte fotos personales e íntimas de paisaje, de sitios visitados y posicionados geográficamente en la red social. Ambos, tanto el fotógrafo de Google como el usuario privado de la web son los generadores de la información visual y de las primeras impresiones realizadas en un tiempo-espacio concreto. Como nómadas proveedores manipulan las fotos de calidad documental, participando, por tanto, en su distribución dentro de la base de datos de Google Earth. Limare (2015, p. 70) explica que las imágenes tomadas por el Google car tienen la voluntad de conquistar el espacio gravitado en el lenguaje del plano americano y en la secuencia cinematográfica del travelling, la cual marca una orientación del encuadre específico según la inclinación de la mirada mecánica e impersonal. También, se compara la función de las cámaras de vigilancia digitales (de techo o pared), que recuperan la 
visión renacentista de uno o dos puntos de fuga (o más centros) determinados por una matriz numérica, reconociendo el espacio y la escena filmada de forma inquisitiva y ordenada.

La segunda categoría está constituida por el flâneur final, el usuario, quien manipula el motor de búsqueda geográfico dejando una nueva marca en la cronofotografía. Además, este usuario construye una auto-ficción observando, viendo, analizando, contemplando y cristalizando procesos de selección y de elaboración detallada del croquis o el dibujo comprometido. Se parte, desde el inicio, de una intención artística que piensa y genera recorridos dentro de los objetos simulados en el mapa, el cual define el contexto de una ruta inmaterial persistente. Dentro de esta ruta se busca restablecer una colección de imágenes que hacen pensar en el uso del ready made digital, que recompone una imagen re-hecha. Asimismo, se camina sobre un sendero de pixels, dispuestos sobre la superficie de la pantalla Led, a partir de diversos enlaces de trayectos determinados por la interface gráfica, traspasando la mirada indiscreta y voyerista sobre la ruta-pantalla. Se reconoce, en esta acción, una lógica de transferencia de información en la que los dos individuos (flâneur fotógrafo y flâneur usuario) se encuentran dentro de un conjunto diametralmente distinto de funciones: uno construye el camino de fotos y el otro camina sobre este. Se trata, por un lado, de un rastro programado por ingenieros en informática que operan el código digital, el lenguaje de la máquina y, por otro lado, se halla un público consumidor, que es usuario de las imágenes buscando integrarse a la red social, a la multitud (Baudelaire, 2010, pp. 17-18). El consumidor de imágenes es un deambulador que se lanza dentro de la geografía virtual, estableciendo una apropiación estética.

\section{Manipulación de las imágenes geográficas en laboratorio: flânerie inicial, avan- zada y última.}

Una práctica de laboratorio en artes visuales implica el empleo de herramientas de exploración y la utilización de tecnologías mediáticas (ordenador, cámara de video, cámaras fotográficas y proyecciones de video), con técnicas de las artes plásticas y visuales. La manipulación de las imágenes geográficas muestran un tratamiento sobre la imagen misma "sin sentido" a partir del uso de técnicas manuales y mecánicas. Ahí, se utilizan los programas de cómputo, que se trabajan mediante ejercicios puntales, con el fin de crear variaciones, modificaciones de las composiciones que pueden eventualmente orientar las prácticas de creación de la obra. Con el propósito de manipular estas imágenes capturadas se establecen cuatro tipos de estrategias que permiten penetrar, identificar, organizar e intervenir la foto y el campo visual.

Cuando se penetra la imagen fotográfica, particularmente, la imagen urbana se hace a partir de una experiencia sensorial y se realiza una selección puntual de la realidad visual representada. Esta acción se logra por medio del croquis (que construye un imaginario básico de conceptos 


\section{Figura 1}

Proceso de composición de una imagen digital a partir del flanerismo virtual. Imagen elaborada en Millumin.

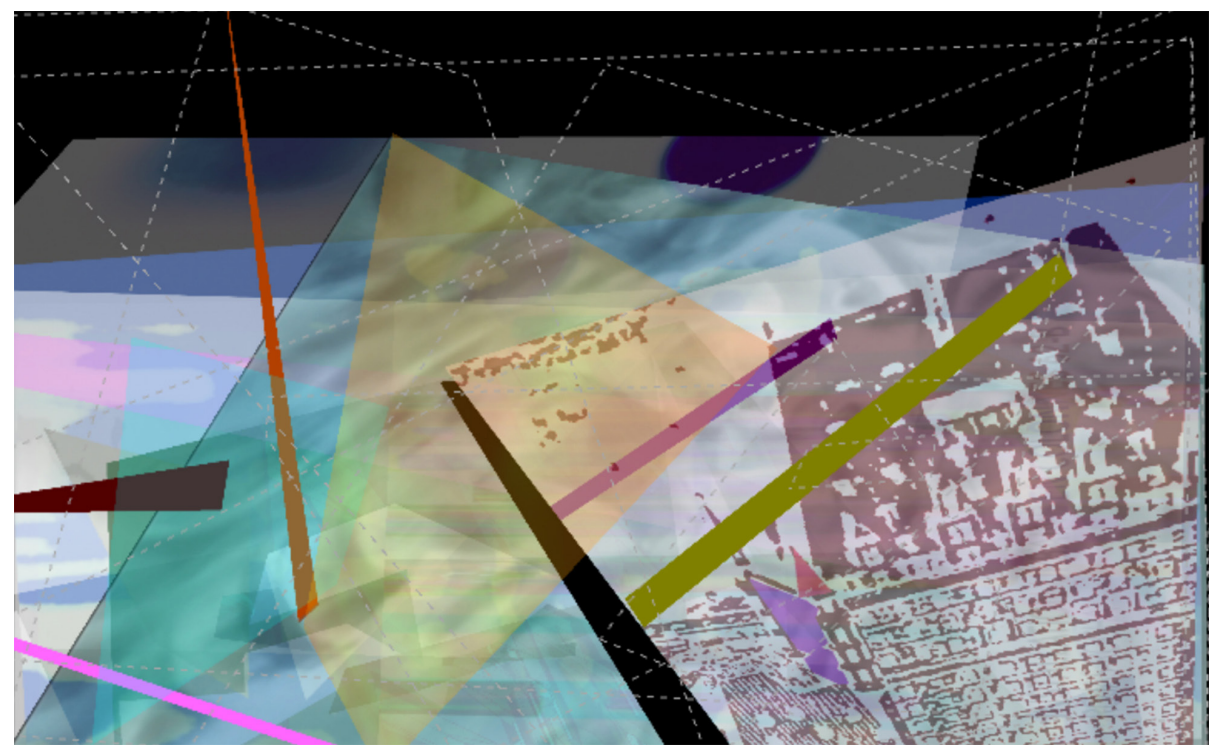

Fuente: Rodolfo Rojas Rocha

gráficos) y el dibujo de bocetos (sobre todo utilizando planos y puntos de vista) que dan cuenta, entonces, de esa interpretación del pasaje urbano profundo, de la ruta citadina apasionada asociada a un tipo de conocimiento sobre los fenómenos complejos (luces, detalles, texturas) que acontecen en la ciudad.

Se podría pensar en Careri (2002), quien establece una identificación del hábitat urbano, cuando se refiere a la lectura de "patrones" de urbe por medio de la deriva situacionista (p. 154) de los landwalks, o la ruta dadaísta (p. 150), que delimita la ciudad como estímulos encontrados por el azar, implantando un tipo circulación conceptual y explicando una serie de elementos iconográficos obtenidos en la imagen urbana. Estos patrones lineales y cromáticos descubiertos por casualidad, coadyuvan a la observación directa del espacio territorial a gran escala, e insertan diversos detalles arquitectónicos dentro de la foto o video. Esta identificación cartográfica conlleva a una serie de operaciones de tipo "Zoom” (Hoelzl \& Marie, 2014), acercándose al detalle de fachadas y de sus estilos arquitectónicos, identificando a la vez, una gramática clara que permite el rastreo de rutas.

En lo que concierne a la intervención sobre la fotografía del globo virtual, se emplean unas estrategias compositivas desde las redes de información y de producción binaria. La intervención, 
sería entonces, una acción concisa de interpretación, diseño, dibujo y apropiación plástica que reconstruye otra versión del original implantando esquemas gráficos que se repiten y no se reconocen en el momento.

Entonces penetrar, identificar, organizar e intervenir ayuda a delimitar tres tipos de flânerie. Se comienza con estas cuatro estrategias que incluyen la flânerie inicial, la cual explora una ciudad o territorio dentro del mapa mundial. El emplazamiento constituye una sensación rotatoria de volumen 3D de los edificios como habitáculos perceptivos localizados en el campo visual aéreo. Con esta acción giroscópica se llega a ser testigo fiel de un panorama mimético y analógico de la zona simulada que instaura un avistamiento de avión y que finge el aterrizaje o el despegue mediante la manipulación de dos cursores ubicados a la izquierda superior de la pantalla.

Allí se encuentra una brújula con indicación norte, sur, este y oeste que regula el eje rotatorio sobre la imagen matricial. Además, existe otro dispositivo que ayuda a un desplazamiento topográfico paralelo al territorio representado del mapa hasta encontrar las poli-líneas emplazadas en los recorridos del automóvil que funciona como dispositivo de entrada. Estas marcan el camino recorrido y se convierten en editores de mapas pasando a la otra fase de ventanas se transforman en imágenes "renderizadas" de fácil acceso. Para activar estas líneas azuladas es necesario mover el pegman en dirección a esas marcas de recorridos haciendo viraje hacia las señales gráficas vectoriales a nivel de la calle. Esta primera entrada a gran escala hacia la foto, en plano panorámico, recuerda las grandes pinturas de paisajes circulares del Barroco y el Romanticismo, hechas con la técnica de trompe-l'oeil en las que se representa las inmensas perspectivas atmosféricas que utilizan los planos de distancia (primer, medio y el último plano).

Con la flânerie avanzada es posible acercarse, a través del ojo de pájaro electrónico, a la superficie de la calle y los alrededores de la acera. Esto implica reconocer la proximidad visual mediante el pegman, el cual penetra concisamente hacia un portal visible que nos lleva a otra dimensión de fotografías. Es como pasar a una segunda puerta en dirección a un espacio paralelo cerca del punto de vista corporal y de nuestra altura corresponde a la posición originaria del conductor quien toma las fotos. Estando allí, se manipula el andar a través de secuencias

\footnotetext{
${ }^{2}$ Es un proceso de generación de imágenes, basado en un modelo 3D por ordenador tomando en cuenta la distribución de la información de la luz y la ejecución de texturas a partir de estructuras poligonales. Esta técnica busca, por lo general, un efecto mimético parecido a la realidad fotográfica, utilizando motores y operadores de simulación visual.
} 
simuladas que se activan mediante la selección de la línea amarilla como señal de tránsito, la que se impulsa la marcha al presionar en la imagen localizada en el centro de la ruta ${ }^{3}$.

Esta operación constituye una manera de navegación inteligente (Hoelzl \& Marie, 2014, p. 265) puesto que el avatar se sumerge en la superficie, transformándose en líneas de orientación agrupadas en elementos y en figuras sobre el plano visual marcado por la frontera de la pantalla.

La flânerie última se orienta dentro de la foto en detalle donde se toman las particularidades, principalmente, en búsqueda de un módulo que se extrae de un sector de la imagen. Así, se logra tener un patrón abstraído de las fachadas, las ventanas, los muebles urbanos y la textura de todo el conjunto. Hay varios tipos de módulos: sobre las fotos, sobre la composición y dentro del recorrido. En fin, cuando se realiza esta marcha se actúa como pintor o dibujante arquitectónico ${ }^{4}$.

El artista contemporáneo flanea y ejerce una mirada hacia la producción simbólica desde un espacio inmaterial según un formato pictórico. Es inevitable, no obstante, que esta tercera operación sea práctica, la cual es determinada por la recolección de esa información pertinente que ayuda a la elaboración proyectual de la potencial obra plástica o visual.

Este paseo por Street View permite reconocer algunas vistas tridimensionales, pasando por la manipulación figurativa de las fotos de geo-localización a la construcción detallada. Esto para integrar algunos principios del arte moderno como la dimensión abstracta que captura la totalidad de la imagen urbana por medio de pautas gráficas. Acá el formalismo tiene su lugar integrándose al proceso de construcción de la obra, ya sea generando una pintura, un grabado o hasta una instalación de video ${ }^{5}$.

\section{Conclusión}

La marcha virtual es la última categoría de experiencias del andar. Esta es, de cierta manera, un último estadio en la que el cuerpo se desmaterializa. Una marcha de visión, podría decirse, determinada por la pulsión ocular donde la cognición y la mente se encuentran a partir de la manipulación de la interface. No requerimos pasaporte para cruzar las fronteras,

${ }^{3}$ Consultar en https://www.google.com/intl/fr/maps/streetview/

${ }^{4}$ Consultar en https://www.google.com/intl/fr/maps/streetview/

${ }^{5}$ Consultar la experiencia de creación digital mediante la utilización del Google Earth por medio del blog que describe todos los procesos concernientes a construir toda una serie de exploraciones hechas por rutas virtuales en http://territoiresartpensetechnologie.blogspot.ca/ 
evitándose las complicaciones de aduana, explorando los itinerarios internacionales, sobrevolando las topografías simuladas, haciendo posible las migraciones en pantalla de pixels. Efectivamente, se entra a un paisaje por desplazamientos de pantalla con el propósito único de la creación artística. Es ahí donde tiene un gran sentido este recorrido por Street View, quel se transforma en un dispositivo de navegación que propone un proyecto de arte hacia la imagen abstracta de los territorios, archivando la herencia cultural de los paisajes fotográficos en 3D.

Trabajar las pantallas implica transformar la ruta en un laboratorio de artes mediáticas en el que el conocimiento técnico fija pautas de posibles lecturas de la ciudad como territorio de re-creación. El walkscape virtual es una acción puntual, ya que el fotógrafo de Google y el flâneur virtual proponen una nueva realidad y un nuevo régimen panóptico privado. Ahí, a partir de estas acciones se llega a enriquecer la experiencia artística vinculada al conocimiento del viaje en línea. Estos caminos simulados se explican por los mundos visitados planteando una ruta por textos, páginas web y videos. Ese vínculo entre deseo gregario, transportación de información y espacio digital podría ser un aspecto a considerar si se toma en cuenta que los saberes sensibles al entorno son determinados por desplazamientos físicos y digitales. En fin, estos paseos virtuales constituyen una serie de operaciones de movilidad de conocimientos en las que la interpretación de datos accesibles vincula las vivencias estéticas a través de motores de búsqueda. Estos actúan, evidentemente, como lugares de migración de imágenes que explican espacios de lectura visual donde se asume una estética virtual híbrida asentada en la cultura visual y digital que inciden en la elaboración de maniobras estéticas in-situ.

\section{Referencias}

Baudelaire, Ch. (2010). Le peintre de la vie moderne. París: Mille et une nuits.

Berdet, M. (2012). Chiffonnier contre flâneur. Construction et position de la Passagenarbeit de Walter Benjamin. Archives de Philosophie, 75(3), 425-447.

Cambier, A. (2009). Quand la ville fait monde.... Cahiers philosophiques, 2(118), 9-21.

Careri, F. (2002). Walkscapes: el andar como práctica estética = Walking as an aesthetic practice: Barcelona: Gili.

Cuvardic García, D. (2009). La reflexión sobre el flâneur y la flânerie en los escritores modernistas latinoamericanos. Káñina, Rev. Artes y Letras, 33(1), 21-35.

Doueihi, M. (2008). La grande conversion numérique. París: Éditions du Seuil. 
Google. (2016). Aventuras de Google Maps. Recuperado de https://www.google.com/maps/ about/behind-the-scenes/streetview/treks/

Google. (2016). Google Street View. Recuperado de: http://www.google.com/maps/about/ behind-the-scenes/streetview/\#trekker

Goldate, S. (1996). The cyberflâneur: Spaces and places on the internet. Art Monthly, 91, 15-18.

Hahn, H. (2006). Du flâneur au consommateur: spectacle et consommation sur les Grands Boulevards, 1840-1914. Romantisme, 134(4), 67-78.

Hoelzl, I. y Marie, R. (2014). Google Street View: navigating the operative image. Visual Studies, 29(3), 261-271.

La Rocca, F. (2011). Techno-oeil: jeux de formes et d'images. Sociétés, 111(1), 71-79.

Lauster, M. (2007). Walter Benjamin's Myth of the "Flâneur. The Modern Language Review, 102(1), 139-156.

Limare, S. (2015). Surveiller et sourire: les artistes visuels et le regard numérique. Montréal: Presses de l'Université de Montréal.

Nuvaloti, G. (2009). Le flâneur dans l'espace urbain. Géographie et cultures, 70, 2-11.

Poissant, L. (2008). Prolifération des écrans. En Poissant, L. y Tremblay. En Prolifération des écrans=Proliferation of screens (11-28). Québec: Presses de l'Université du Québec/Ryerson University.

Provost. L. (5 de octubre del 2016). Street View: On a t++esté le sac à dos "trekker" qui photographie les lieux les plus retranchés de la planète pour Google. Huffpost. Reuperado de http://www.huffingtonpost.fr/2014/09/30/street-view-trekker-photographie-google-test_n_5902940.html

Simay, P. (2009). Walter Benjamin: la ville comme éxpérience. En Thierry, P. (Ed.). La décourverte, (73-77).

Territoires de l'art. (2016). Semaine 1 Module et dispositif 37-2 Art de la Rue Saint-Jean BaptisteRecuperado de http://territoiresartpensetechnologie.blogspot.ca/2014/08/semaine-1-module-et-dispositif-37-2-art.html?q=module 